\title{
CORRIGENDUM
}

to

\section{“THE SPATIAL AND TEMPORAL AVAILABILITY DIFFERENCES OF CLOUD-FREE LANDSAT IMAGES OVER THREE GORGES RESERVOIR AREA”}

by B. X. Bai, Y. M. Tan, and P. Wu,

Int. Arch. Photogramm. Remote Sens. Spatial Inf. Sci., XLII-3/W9, 1-8, 2019.

The following paper has to be considered as a replacement of the originally published version. The paper was sent by mistake in an incorrect version to the Copernicus Service Provider. Corrected issues: Due to a formatting issue, captions of Figures 3 and 5 were not correctly attached.

The editors apologize with the authors for the inconvenience.

4 November 2019 


\title{
THE SPATIAL AND TEMPORAL AVAILABILITY DIFFERENCES OF CLOUD-FREE LANDSAT IMAGES OVER THREE GORGES RESERVOIR AREA
}

\author{
Bingxin Bai, Yumin Tan *, Peng Wu \\ School of Transportation Science and Engineering, Beihang University, Beijing 100191, China - (baibx, tanym, \\ wupeng123)@buaa.edu.cn
}

Commission III, WG III/8

KEY WORDS: Cloud Cover, Landsat, Acquisition Probability, Google Earth Engine (GEE), Three Gorges Reservoir Area

\begin{abstract}
:
Availability analysis of cloud-free optical remote sensing data is a prerequisite for remote sensing applications. In this study, spatiotemporal availability differences of cloud-free Landsat TM, ETM+, and OLI sensors images over Three Gorges Reservoir Area (TGRA) were analyzed from 1986 to 2019 based on the Google Earth Engine (GEE). The results show that: 1) in Summer, especially in August, the probabilities of obtaining Landsat images with no more than $30 \%$ cloud cover (CC) is higher. 2) the northeast of TGRA has higher probability of acquiring cloudless images than the southwest. 3) In TGRA, annual monitoring which require at least one cloud-free observation in a year largely unaffected by $\mathrm{CC}$, but when considering seasonal monitoring, cloud contaminate will become a limitation, and monthly monitoring in this area is basically not feasible even if the three sensors data are combined. The results of this paper will provide important references for the research of using optical data in this area, and although the research area is relatively small, the analysis method and the program developed in this paper have no restrictions on the area.
\end{abstract}

\section{INTRODUCTION}

Landsat has become the most commonly used optical remote sensing data in the study of regional time series analysis because of its long history of surface observation, high spatial resolution, and free access policy. However, the most obvious challenge for their application is cloud cover (CC) and cloud shadows (Kovalskyy and Roy, 2013; Asner, 2001), particularly in some tropics. Although the Landsat satellite can overpass the same location on earth every 16 days, but due to cloud contamination, in some areas, the interval between two cloudless observations is often greater than 16 days, some even last as long as a year (Bai et al. 2019). Thus, analysis the availability of Landsat images is a paramount prerequisite for many optical remote sensing applications.

Three Gorges Reservoir Area (TGRA) is a popular independent research area since the construction of the Three Gorges Dam. With millions of immigrants and the reservoir began to impound, the land use/land cover in the region has undergone rapid and tremendous changes in the past decade. Researches on land use/land cover change detect (Zhang et al. 2009; Tan et al. 2016), forest monitoring (Zeng et al. 2008), water monitoring (Wang et al. 2013) and geological hazards (Tan et al. 2015) in this area has been carried out continuously. Most of these researches are based on optical remote sensing data. Availability analysis of optical data can provide a comprehensive understanding of the data situation and help to select data when conducting research in the region. To our knowledge, cloud cover analysis of all available Landsat data (TM, ETM+ and OLI in particular) over TGRA has not been reported to date. Although the availability analysis of Landsat 8 data in China has been carried out (Xiao et al. 2018), but the study of country scale will weaken the statistical characteristics of region scale, and only the data of Landsat 8 were analyzed.
Many studies (Asner, 2001; Sano et al. 2007; Kovalskyy and Roy, 2013; Ju and Roy, 2008) have analyzed the availability of optical data in different parts of the world. Li et al. (2018) studied the acquisition probability differences in cloud coverage of the available Landsat observations over mainland Southeast Asia. Laborde et al. (2017) analyzed the Landsat 8 cloud-free observations in South East Asia. Xiao et al. (2018) analyzed the spatio-temporal differences in cloud cover of Landsat-8 OLI across China. Sano et al. (2007) studied the spatial and temporal probabilities of obtaining cloud-free data of Landsat TM, ETM+ over the Brazilian tropical savanna. These studies mostly download the Landsat metadata from the USGS portal, process and analyze locally, which takes a long time to calculate, such as Sano et al. (2007) took about 208 days in their study.

As supercomputers and high-performance computing systems are becoming more and more abundant, large-scale cloud computing as a commodity is widely available. Google Earth Engine (GEE) is one of the cloud-based platforms that can processing large-scale of geospatial datasets (Gorelick et al. 2017). The platform houses a large repository of publicly available geospatial datasets, users can access and analyze data on this platform without download it. Since there is no need to download the data locally, the algorithm runs in the cloud, which makes a lot of work more efficient (Li et al. 2019). Based on this, we studied data availability based on GEE, and as far as we know, there is no research done this yet.

In this study, more than thirty years (from April 1986 to January 2019) Landsat 5/7/8 TM, ETM+, and OLI historical data (a total of 10876 scenes) were used to evaluate the monthly and yearly availability of Landsat data over TGRA, unlike other similar research methods, this paper uses GEE to analyze the availability of Landsat data, which greatly improves the efficiency. and a series of tools for data availability analysis are developed based on GEE. The objective of this study is twofold: (1) to understand the spatial and temporal availability of

\footnotetext{
Corresponding author: Yumin Tan. Email: tanym@buaa.edu.cn
} 
Landsat TM, ETM+, and OLI sensors in TGRA; (2) to assess the feasibility of using Landsat satellite series for annual, seasonal or monthly monitoring in this region or the impact of $\mathrm{CC}$ on these tasks.

\section{MATERIALS AND METHODS}

\subsection{Study Area}

The Three Gorges Reservoir Area (Figure 1) refers to the area inundated by the Yangtze Three Gorges Project, located in the central territory of the Yangtze River $\left(105^{\circ} 44^{\prime}-111^{\circ} 39^{\prime} \mathrm{E}, 28^{\circ}\right.$ $\left.32^{\prime}-31^{\circ} 44^{\prime} \mathrm{N}\right)$, covering an area of approximately $5800 \mathrm{~km}^{2}$ (Wu et al. 2004). It is an important ecological buffer of the Yangtze River basin. Due to the impact of the largest hydraulic project in the world - the Three Gorges Dam, as well as the migrant's resettlement, it has experience, extensive and rapid land cover and land use change and has been a hot area with numerous ecological environment issues in the past two decades. The reservoir area belongs to the subtropical and humid climate, with a mean annual precipitation of $1250 \mathrm{~mm}$. After the Three Gorges impoundment, the area of the water area enlarged and the evaporation of water increased, the weather here is cloudy and foggy throughout the year. It is hard to obtain cloud-free or little cloudy images in this area.

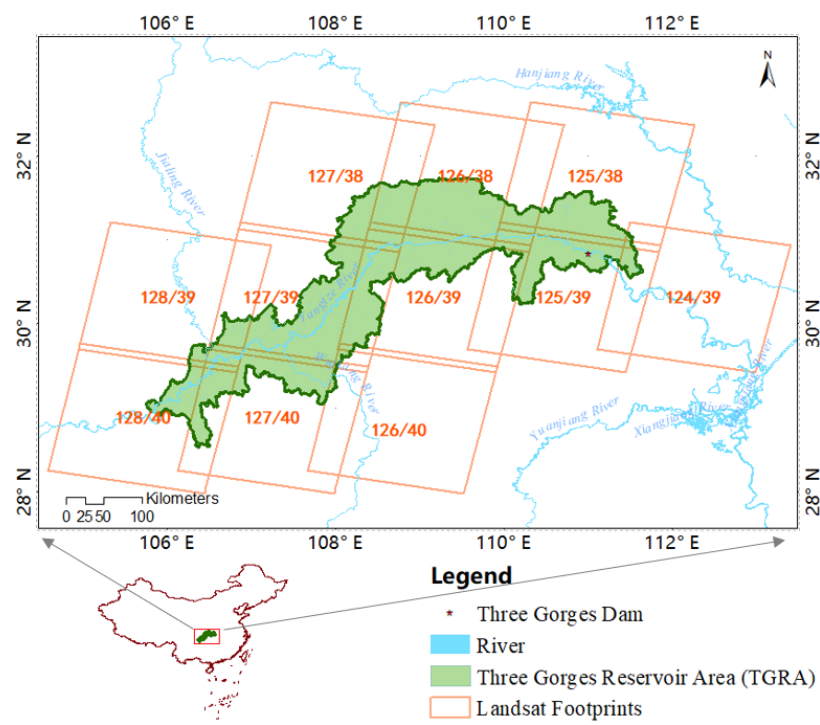

Figure 1. The location of the Three Gorges Reservoir Area (TGRA) and the 11 Landsat footprints (path/row) over this region.

\subsection{Data and Analysis Platform}

Landsat data can obtain about $183 \mathrm{~km} \times 170 \mathrm{~km}$ scenes defined in a Worldwide Reference System (WRS-II) of path and row coordinates (http://landsat.usgs.gov/tools_wrs-2_shapefile.php) ( $\mathrm{Ju}$ and Roy, 2008), and there are $11^{-}$path and row (PR) coverage frames (or footprints, e.g., 128/39) of Landsat satellite over TGRA (Figure 1).

The data used in this paper are shown in Table 1. Since the GEE platform has uploaded the Landsat data of USGS, we calculate and analyze the data directly on GEE platform (https://code.earthengine.google.com/) instead of downloading it. The USGS produces data in 3 categories for each satellite: Tier 1 (T1), Tier 2 (T2) and Real Time (RT). The data that meets geometric and radiometric quality requirements are Tier 1 data, while the unsatisfactory data is Tier 2 data. The RT data is unevaluated data (it takes as much as a month). Newly captured scenes are added to the T1_RT collection daily. When an RT scene is reprocessed, it will be classified as $\mathrm{T} 1$ or $\mathrm{T} 2$, which will be removed from T1_RT (Google Developers, 2019). As the time node of the data used in this paper is January 2019, it is not sensitive to removals or potentially mis-registered scenes.

\begin{tabular}{|c|l|l|}
\hline Data & \multicolumn{1}{|c|}{ Data ID on GEE } & \multicolumn{1}{c|}{ Time } \\
\hline \multirow{2}{*}{$\begin{array}{l}\text { Landsat } \\
5 \mathrm{TM}\end{array}$} & LANDSAT/LT05/C01/T1_SR & $\begin{array}{l}\text { Jan 1, 1984- } \\
\text { May 5, 2012 }\end{array}$ \\
\cline { 2 - 3 } & LANDSAT/LT05/C01/T2 & $\begin{array}{l}\text { Jan 1, 1984- } \\
\text { May 5, 2012 }\end{array}$ \\
\hline \multirow{2}{*}{$\begin{array}{l}\text { Landsat } \\
\text { 7 ETM+ }+\end{array}$} & LANDSAT/LE07/C01/T1_RT & $\begin{array}{l}\text { Jan 1, 1999- } \\
\text { Jan 1, 2019 }\end{array}$ \\
\cline { 2 - 3 } & LANDSAT/LE07/C01/T2 & $\begin{array}{l}\text { Jan 1, 1999- } \\
\text { Jan 1, 2019 }\end{array}$ \\
\hline \multirow{2}{*}{$\begin{array}{l}\text { Landsat } \\
\text { OLI }\end{array}$} & LANDSAT/LC08/C01/T1_RT & $\begin{array}{l}\text { Apr 11, 2013- } \\
\text { Jan 1, 2019 }\end{array}$ \\
\cline { 2 - 3 } & LANDSAT/LC08/C01/T2 & $\begin{array}{l}\text { Apr 11, 2013- } \\
\text { Jan 1, 2019 }\end{array}$ \\
\hline
\end{tabular}

Table 1. Data used in this study.

It should be note that the $\mathrm{T} 2$ data is usually useless, but when calculating the probability of data acquisition, we consider T2 data, which is reasonable, because T2 data will affect the probability of acquisition. But in calculating the number of cloud-free data, we did not take T2 data into account. This is because the cloud cover of $\mathrm{T} 2$ data also have low value like $10 \%$ or $5 \%$, but this kind of data is still invalid and unuseful. When we do the statistics of cloud-free data, we use the cloud cover threshold to filter the data. If the T2 data be considered, the result will be wrong and unreferential.

The thresholds of cloud cover range from 0 to $100 \%$ in the Landsat data, which can be divided into ten levels (0-9) at 10\% intervals (Asner, 2001). Level 0 represents the CC of scenes no more than $10 \%$ (or $0 \% \leqslant \mathrm{CC} \leqslant 10 \%$ ), and level 1 represents the range from $10 \%$ to $20 \%$ (including $20 \%$ ). Following this categorization, the level 9 represents greater than $90 \%$, but less than or equal to $100 \%$ (or $90 \%<\mathrm{CC} \leqslant 100 \%$ ). CC thresholds are referred as $0 \%, 10 \%$ to $100 \%$ or level 0 , level 1 to level 9 in this study.

In total, there were 10876 scenes (Table 2) of Landsat available over TGRA from April 1986 to January 2019, comprising 5342 TM scenes (1986-2011), 4128 ETM+ scenes (1999-2019), and 1406 OLI scenes (2013-2019). The number of these data statistics at different cloud levels are shown in Table 2. The statistics in front of the slash includes T1, RT and T2 data, while the statistics after the slash removes the T2 data. As can be seen from Table 2, with the removal of $\mathrm{T} 2$ data, the number decreases greatly, especially in the CC levels of 9 . 


\begin{tabular}{cccccccccccc}
\hline Sensors & Total & \multicolumn{10}{c}{ cloud cover (CC) levels } \\
\cline { 3 - 12 } & scenes & 0 & 1 & 2 & 3 & 4 & 5 & 6 & 7 & 8 & 9 \\
\hline Landsat 5 & $5342 /$ & $735 /$ & $339 /$ & $311 /$ & $250 /$ & $245 /$ & $279 /$ & $285 /$ & $312 /$ & $385 /$ & $2201 /$ \\
TM & 2565 & 617 & 249 & 230 & 207 & 207 & 235 & 233 & 245 & 213 & 129 \\
\hline Landsat 7 & $4128 /$ & $517 /$ & $268 /$ & $196 /$ & $207 /$ & $188 /$ & $199 /$ & $212 /$ & $210 /$ & $284 /$ & $1847 /$ \\
ETM+ & 2238 & 493 & 255 & 189 & 194 & 179 & 190 & 191 & 176 & 173 & 198 \\
\hline Landsat 8 & $1406 /$ & $136 /$ & $89 / 78$ & $76 / 68$ & $60 / 55$ & $74 / 70$ & $81 / 73$ & $61 / 60$ & $85 / 82$ & $110 / 98$ & $634 / 126$ \\
OLI & 833 & 123 & & & & & & & & & \\
\hline
\end{tabular}

Table 2. Landsat TM, ETM+, and OLI scenes acquisition statistics in TGRA and the number of scenes at varies cloud cover (CC) levels (0-9) from April 1986 to January 2019. (Note: Statistics that do not contain Tier 2 data sets are behind the slashes.)

\subsection{Acquisition Probability Calculation of Different CC Thresholds}

For each land scene at footprint, the acquisition probability (AP) of a successful acquisition $(S)$ in a given month $(m)$ was calculated using formula (1) (Asner 2001).

$$
A P(S)_{t}^{m}=\frac{\sum_{y} S_{t}^{m}}{N}
$$

where $m=$ a given month (January, ...)

$y=$ a given year (i.e., between 1986 and 2018)

$t=$ the CC thresholds $(0,10 \%, \ldots$, or $100 \%)$

$N=$ the total number of observation scenes in month $m$ in the entire Landsat historical archive.

Similarly, the annual probabilities are calculated per year rather than per month. The calculation and analysis of AP etc. in this paper are carried out on the GEE platform.

\section{RESULTS AND DISCUSSION}

\subsection{Monthly Average Acquisition Probability Differences among TM, ETM+, and OLI Sensors}

In order to study the acquisition probability varies at different cloud cover thresholds, 10876 scenes of Landsat TM, ETM+, and OLI sensors in TGRA acquired from April 1986 to January 2019 were used to obtain the monthly cumulative acquisition probability (Figure 2). As 30\% threshold of CC likely represents the maximum allowable value for land-cover analyses. The $10 \%, 20 \%, 30 \%$ thresholds of CC were mainly concerned and selected in this study to the statistical analysis.

It can be seen that the cumulative acquisition probability curve has risen sharply in the cloud cover range of $90 \%-100 \%$, indicating that most of the data acquired in TGRA have more than $90 \%$ CC. The monthly acquisition probability curves are in the shape of a willow. At the CC threshold of $30 \%$, the average monthly acquisition probability of the Landsat TM, ETM+, and OLI sensors is $0.259,0.246,0.225$ respectively, less than the Landsat OLI acquisition probability of $49.6 \%$ in China at $30 \%$ CC threshold (Xiao et al. 2018). For Landsat TM sensor, at 30\% $\mathrm{CC}$ threshold, the acquisition probability is highest in August (0.340), followed closely by May, and lowest in January (0.160), followed by February and December. For Landsat ETM+ sensors, the highest probability of acquisition images with $\mathrm{CC}$ no more than $30 \%$ is in July $(0.320)$ and August, while the lowest probability in February $(0.170)$, followed by December. As for the Landsat OLI sensor, the acquisition probability is highest in August (0.369), followed by October and July, lowest in March (0.131), followed by March and February.

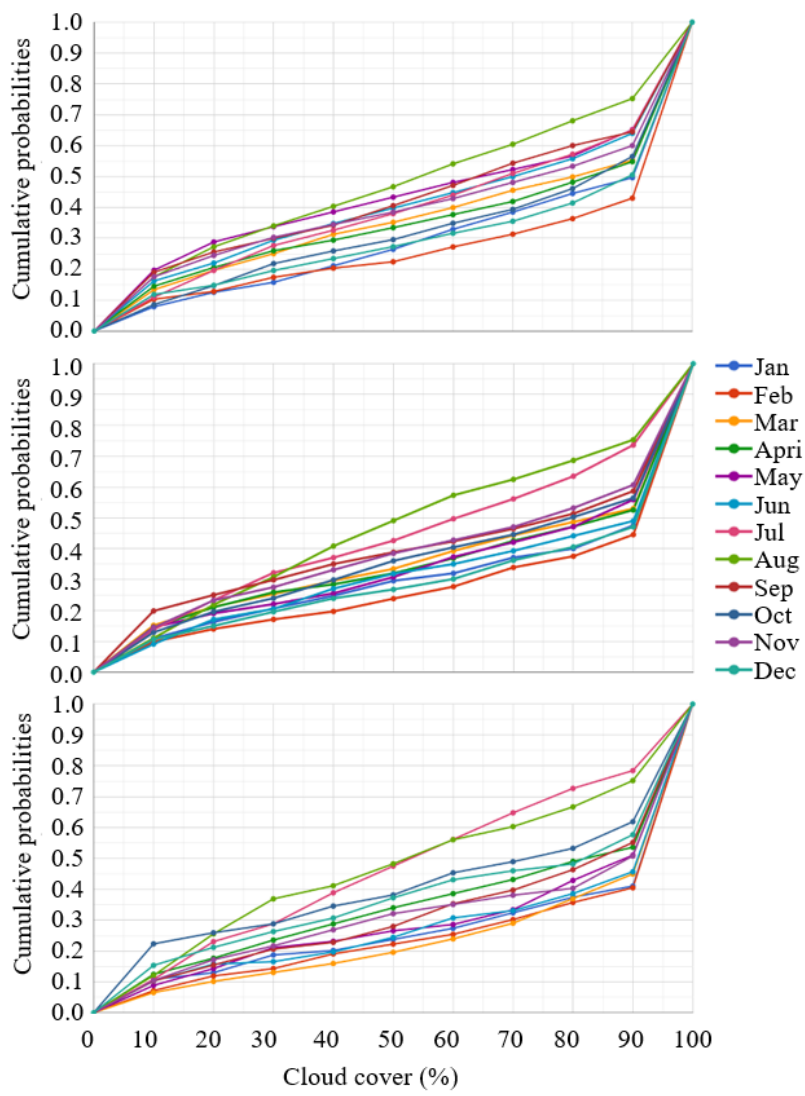

Figure 2. The cumulative average monthly acquisition probabilities (APs) of different CC thresholds range from 0 $100 \%$ for all Landsat scenes of TM, ETM+, and OLI sensors in TGRA.

Spatially, the acquisition probability of Landsat in the TGRA has some spatial differences at the $30 \%$ CC threshold, especially in winter (December-February), the difference between Northeast and southwest is obvious (Figure 3), and the acquisition probability in the northeast is greater than that in the southwest. In December, the probability of obtaining cloud-free Landsat is the lowest that $63 \%$ of the scenes showed less than a $20 \%$ chance of obtaining images with no more than $30 \%$ CC. In Spring (March-May) and Summer (June-August), the probability is higher, especially in August and July. The chances of getting no more than $30 \%$ CC images in $80 \%$ of the scenes of TGRA is more than $30 \%$ in August. 

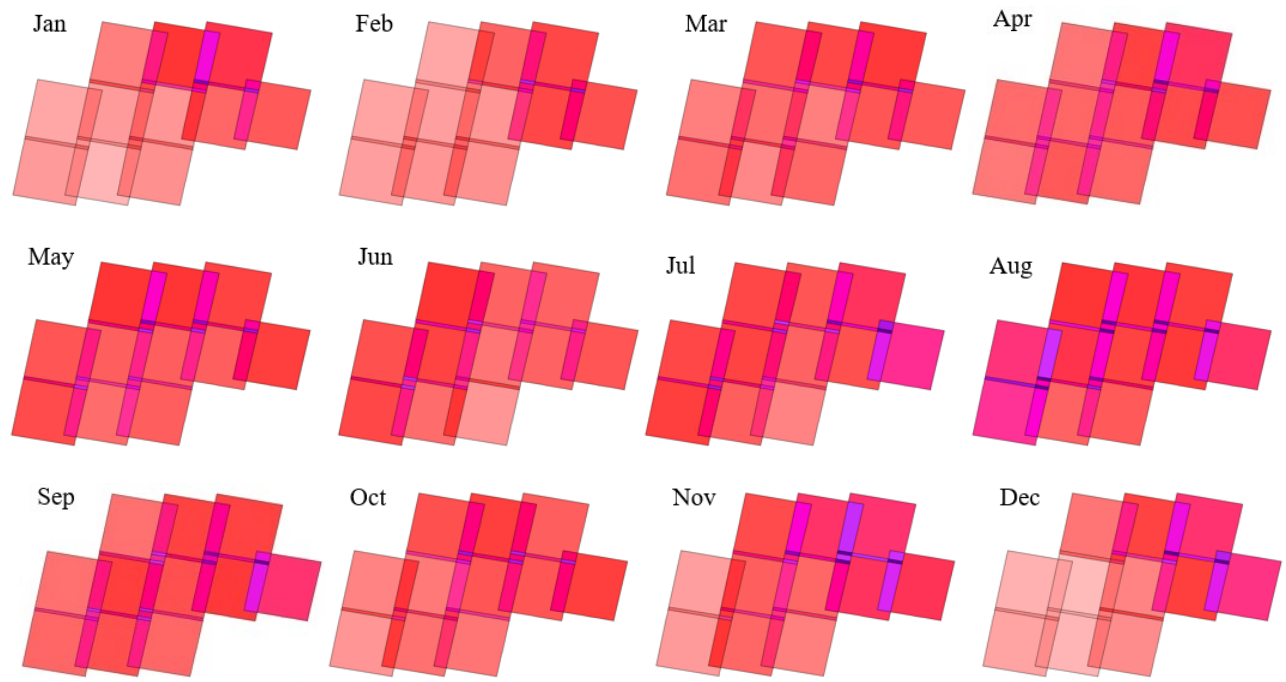

Acquisition Probabilities (AP)

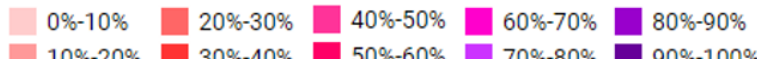

Figure 3. Monthly average of acquisition probability of Landsat TM, ETM+, and OLI historical data over TGRA between 1986 and 2019 at $30 \%$ or less CC thresholds.

\subsection{Annual Average Acquisition Probability Differences among TM, ETM+, and OLI Sensors}

In order to analyze the spatial difference of the annual acquisition probability of cloud-free data in TGRA, the yearly average of acquisition probabilities of Landsat historical data over TGRA between 1986 and 2019, including data from TM, ETM+, and OLI sensors at $10 \%, 20 \%$, and $30 \%$ CC thresholds were mapped (Figure 4). It can be seen from Figure 4 that the north-eastern part of the TGRA (the head of the TGRA) has a higher probability of obtaining cloud-free data. In contrast, the acquisition probability in the southwest is lower. In most areas of the TGRA, the probability TM acquiring no more than $10 \%$ $\mathrm{CC}$ is between $20 \%$ and $30 \%$. Although the probability of acquisition increases with the increase of cloud threshold, the acquisition probability is just about $20 \%-40 \%$ in $90 \%$ of the TGRA at 30\% CC threshold even for the TM sensor which has relatively high $\mathrm{AP}$, and in the northeast, it is $30 \%-40 \%$.
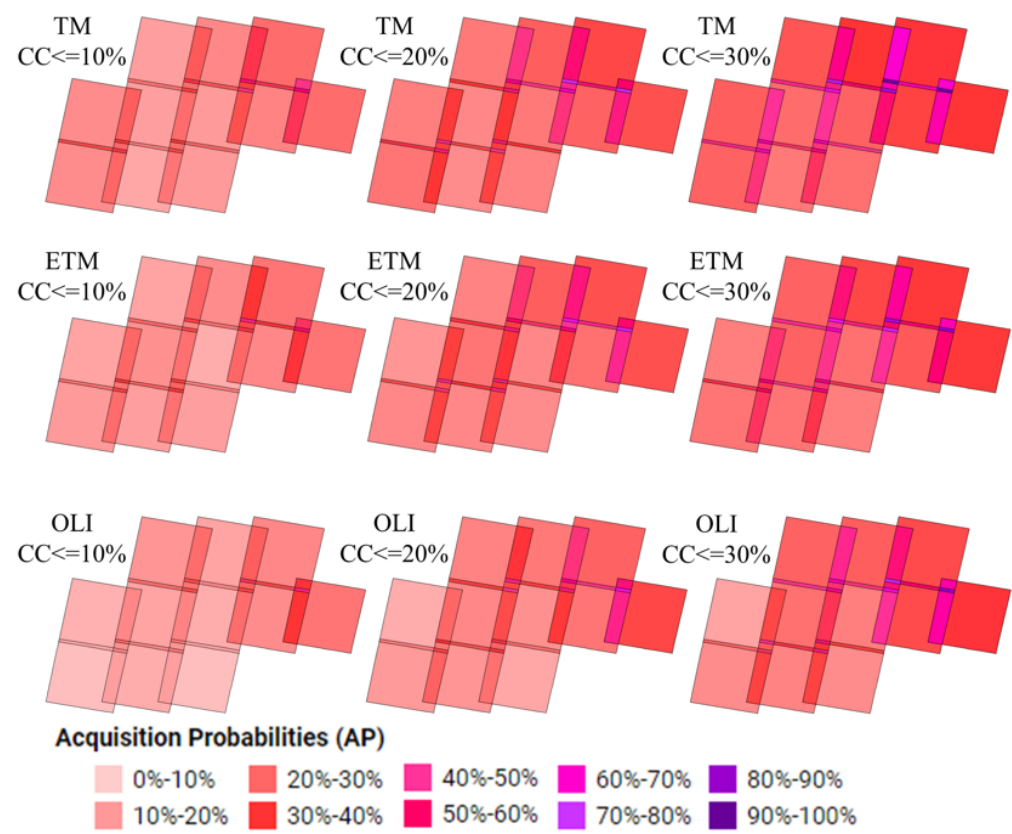

Figure 4. Yearly average of acquisition probabilities of Landsat TM, ETM+, and OLI historical data (10876 scenes) at 10\%, 20\%, and 30\% CC thresholds over TGRA between 1986 and 2019.

\subsection{Spatial Distribution of Cloudless Data Count}

Satellite available data statistics can intuitively display the number of available data. For this reason, we have developed a tool on GEE platform to generate the spatial distribution of cloudless Landsat data based on the work of Li et al. (2019). As shown in Figure 5, the left map is a query condition, and 
different conditions are set to generate the number of observations satisfying the condition. The right one is the spatial distribution of count of Landsat 8 with less than $20 \%$ cloud cover over the TGRA which satisfied the conditions set on the left. Note that the statistics do not include T2 data. As can be seen from the results of the query, only one scene of Landsat 8 is available for some region in a year.

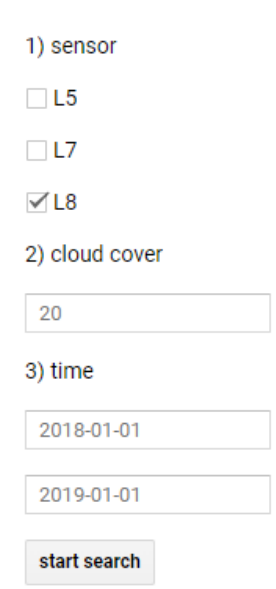

a) Conditional query interface;

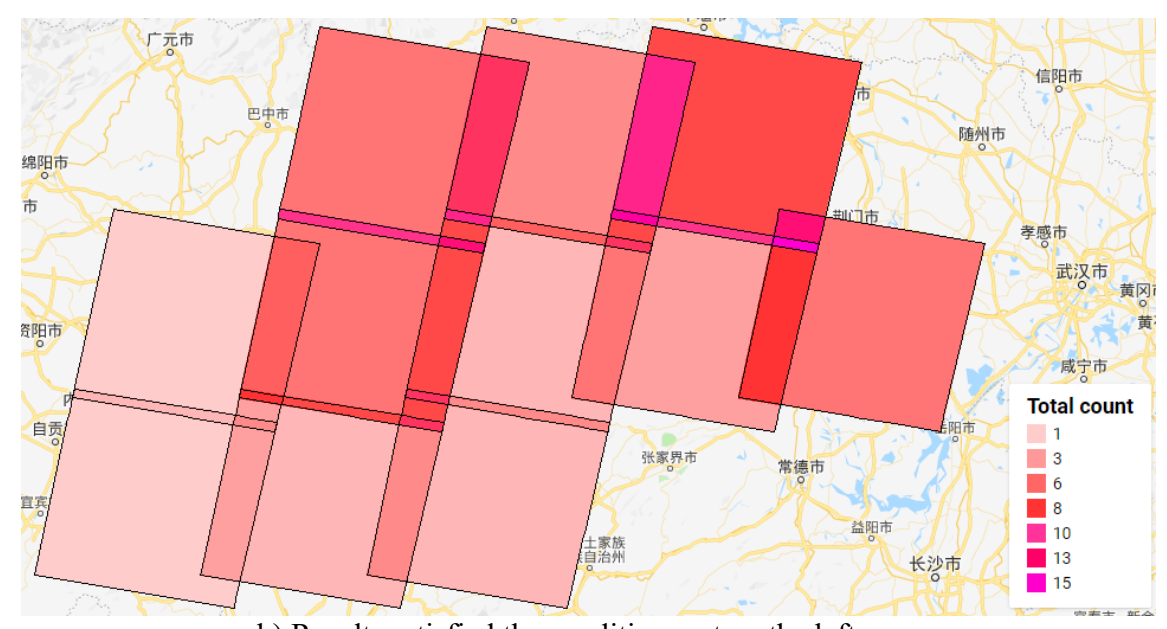

b) Results satisfied the conditions set on the left.

Figure 5. Landsat spatial distribution of Landsat data archives in Three Gorges Reservoir Area.

\subsection{Time Distribution Analysis of Available Data for The Area Covered by One Scene}

The low probability of cloud-free data acquisition in some area is the key to restrict regional monitoring. Considering the low probability of cloud-free data acquisition in the southwestern region of TGRA, we made time distribution statistics for all the Landsat TM, ETM+, and OLI historical data (T1 and RT) on a footprint (path/row is 127/39) in the region to analyze the feasibility of monthly, quarterly and annual land surface change monitoring in the TGRA (Figure 6). The time distribution map of remote sensing archived data based on a scene can clearly show the time distribution of available data that meet certain conditions (like CC no more than $10 \%, 20 \%$ or $30 \%$ ) in the area covered by the scene, thus helping to analyze and determine the time granularity (monthly, seasonal or annual) of monitoring a land surface change or select data for image fusion.

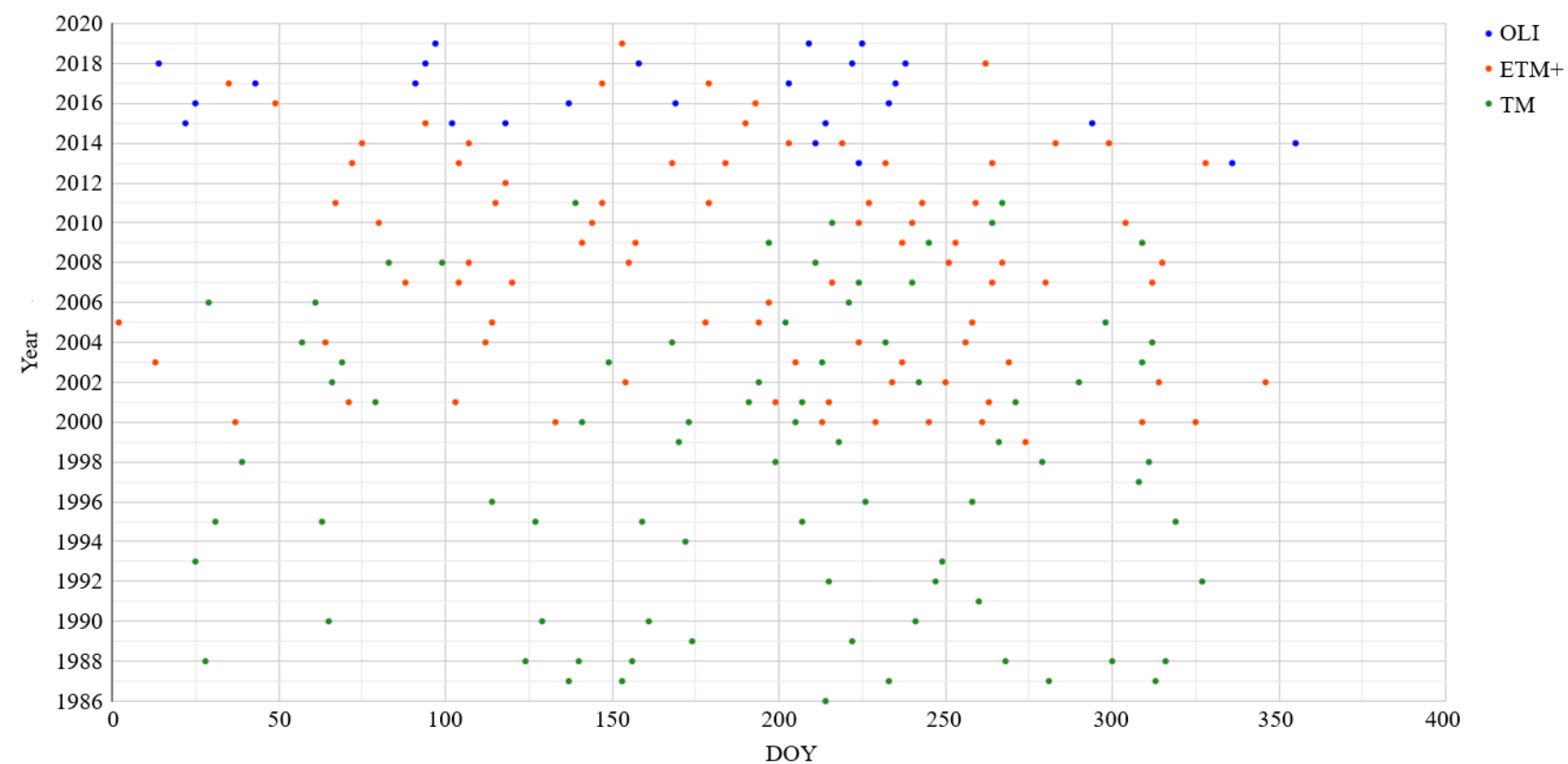

Figure 6. Time Distribution of history archive data of Landsat TM, ETM + and OLI at Cloud Coverage threshold $<=30 \%$ over one scene (path/row:127/39) footprint. (DOY means the day of year)

The time distribution of history archive data from Landsat TM, ETM+ and OLI sensors at 30\% CC threshold over the footprint of 127/39 is shown in Figure 6. The origin indicates that one scene contains less than or equal to $30 \% \mathrm{CC}$, and the minimum distance between the two origins of the same colour is the revisit period of the Landsat satellite, 16 days. As can be clearly 
seen from Figure 6,1) As time goes on, more and more data are available in this area, from the previous TM sensor alone, to the later ETM+ and OLI sensors. Multiple satellite sensors work simultaneously make more data captured; 2) The available Landsat data with $\mathrm{CC}$ no more than $30 \%$ is less in winter (DOY:1-59/60,335/336-365/366) and mostly distributed in summer (DOY:152/153-243/244); 3) Since 1986, there are at least one scene image with no more than $30 \% \mathrm{CC}$ in the area every year, even if only Landsat TM sensor is considered. In 2000, TM and ETM+ combine acquired 11 observations with CC Less than $30 \%$, indicating that annual monitoring in the region is feasible; 4) It is difficult to carry out seasonal monitoring in this region, as some years like 2007-2012 are lack of qualified data in the winter. If the division of seasons is not so strict (i.e., the data of one season can be replaced by the data of the end of the last season or the beginning of the next season) and multi-sensor combination is considered, it is feasible to use Landsat for seasonal monitoring in some years; 5) Since 19862019 , no year has cloud-free data per month, even in the case of a three-sensor combination, which means that it is almost impossible to use Landsat only for monthly monitoring in TGRA.

\section{CONCLUSIONS}

The special weather conditions in the TGRA make it difficult to obtain cloud-free remote sensing images in the area. As the basic work for the study of land surface change monitoring, time series analysis and data fusion in the region, this paper analyzes the historical archive data of Landsat series satellites (TM, ETM+ and OLI) from April 1986 to January 2019 in TGRA. Based on the GEE, total 10876 scenes of Landsat historical archive data were analyzed quickly by means of acquisition probability, spatial difference mapping and time distribution mapping. The statistical analysis shows that in summer, especially in August, the probabilities of acquiring Landsat images with cloud cover no more than $30 \%$ is higher, and the probability of obtaining similar data in winter is less. The acquisition probability of cloud-free data in the TGRA is different in spatial distribution, especially in the winter, and the probability of obtaining data with no more than $30 \% \mathrm{CC}$ in the northeast is greater than that in the southwest. Considering that the southwestern part has the lower probability of obtain cloudfree data which will restrict the surface monitoring tasks of the entire TGRA, the time window diagram of remote sensing data is used to plot the time distribution of the cloud-free data of some area covered by a certain footprint in the southwest. The analysis results show that it is feasible to carry out annual change monitoring tasks in the TGRA. But even considering the combined use of data from different Landsat sensors, due to the lack of data from winter, it is still difficult to use the Landsat family data for seasonal monitoring tasks in some years. As month-monitoring task require shorter time interval of cloudfree data, it is almost impossible to use only Landsat family data for such monitoring tasks in this region.

The lack of cloud-free data will limit the implementation of surface monitoring tasks based on remote sensing in the region, especially for seasonal and monthly monitoring. This suggest the need for the development of new approaches to mitigating cloud contamination in the TGRA. With the development of remote sensing big data, especially the emergence of platform like Google Earth Engine which provides a good tool for data processing (Gorelick et al. 2017). It is more economical and effective to form high-frequency cloud-free data by combining sub-scenes. In addition, with more and more of remote sensing satellites launched, and increasing remote sensing data are available free of charge, such as the Sentinel series, fusion multi-source remote sensing data (Bai et al. 2019), or adopt radar data (Reiche et al. 2015) is also an option.

The results and conclusions provide useful information for the remote sensing application in this region, are the practical guidance for selecting cloudless Landsat data for land cover change monitoring, time series analysis, or multi-source remote sensing fusion research in TGRA. As many Landsat application often require at least one cloud-free observation in two different seasons, or at least a pair of cloud-free observations occurring no more than $16,32,48,64$, and 80 days apart within a year and season. The feasibility of carrying out these frequency monitoring tasks in this area can be studied in the future. Although the research area of this paper is relatively small, the analysis method and the program developed in this paper have no restrictions on the area, it will be easy to get a wide range of results by slightly changing some programs.

\section{ACKNOWLEDGEMENTS}

Thanks to Masum Syed Mohammad for helping to improve the translation of this article. This research was funded by Projects for Follow-up Work in Three Gorges 'Development of Integrated Management Network and Spatial Information Service Platform in Three Gorges Reservoir Area' (2017HXNL-01) and 'Research on Spatial Information Technology Application of Immigrant Urban Community Management and Tourism Development in Three Gorges Reservoir Area' (12610100000018J107).

\section{REFERENCES}

Asner, G.P., 2001. Cloud cover in Landsat observations of the Brazilian Amazon. Int. J. Remote Sens., 22, 3855-3862. doi.org/10.1080/01431160010006926.

Bai, B., Tan, Y., Guo, D., Xu, B., 2019. Dynamic Monitoring of Forest Land in Fuling District Based on Multi-Source Time Series Remote Sensing Images. ISPRS Int. J. Geo-Information, 8, 36. doi.org/10.3390/ijgi8010036.

Google Developers, 2019. Landsat collection structure. https://developers.google.com/earth-engine/landsat September 2019).

Gorelick, N., Hancher, M., Dixon, M., Ilyushchenko, S., Thau, D., Moore, R., 2017. Google Earth Engine: Planetary-scale geospatial analysis for everyone. Remote Sens. Environ., 202, 18-27. doi.org/10.1016/j.rse.2017.06.031.

Ju, J., Roy, D.P., 2008. The availability of cloud-free Landsat ETM + data over the conterminous United States and globally. Remote Sens. Environ., 112, 1196-1211. doi.org/10.1016/j.rse.2007.08.011.

Kovalskyy, V., Roy, D.P., 2013. The global availability of Landsat $5 \mathrm{TM}$ and Landsat $7 \mathrm{ETM}+$ land surface observations and implications for global $30 \mathrm{~m}$ Landsat data product generation. Remote Sens. Environ., 130, 280-293. doi.org/10.1016/j.rse.2012.12.003.

Laborde, H., Douzal, V., Piña, H.A.R., Morand, S., Cornu, J.F., 2017. Landsat-8 cloud-free observations in wet tropical areas: A case study in South East Asia. Remote Sens. Lett., 8, 537-546. doi.org/10.1080/2150704X.2017.1297543. 
Li, H., Wan, W., Fang, Y., Zhu, S., Chen, X., Liu, B., Hong, Y., 2019. A Google Earth Engine-enabled software for efficiently generating high-quality user-ready Landsat mosaic images. Environ. Model. Softw., 112, 16-22. doi.org/10.1016/j.envsoft.2018.11.004.

Li, P., Feng, Z., Xiao, C., 2018. Acquisition probability differences in cloud coverage of the available Landsat observations over mainland Southeast Asia from 1986 to 2015. Int. J. Digit. Earth., 11, 437-450. doi.org/10.1080/17538947.2017.1327619.

Reiche, J., Verbesselt, J., Hoekman, D., Herold, M., 2015. Fusing Landsat and SAR time series to detect deforestation in the tropics. Remote Sens. Environ., 156, 276-293. doi.org/10.1016/j.rse.2014.10.001.

Sano, E.E., Ferreira, L.G., Asner, G.P., Steinke, E.T., 2007. Spatial and temporal probabilities of obtaining cloud-free Landsat images over the Brazilian tropical savanna. Int. J. Remote Sens., $28, \quad 2739-2752$. doi.org/10.1080/01431160600981517.

Tan, Y., Guo, D., Xu, B., 2015. A geospatial information quantity model for regional landslide risk assessment. Nat. Hazards., 79, 1385-1398. doi.org/10.1007/s11069-015-1909-1.

Wang, X., Chen, Y., Song, L., Chen, X., Xie, H., Liu, L., 2013. Analysis of lengths, water areas and volumes of the Three Gorges Reservoir at different water levels using Landsat images and SRTM DEM data. Quat. Int., 304, 115-125. doi.org/10.1016/j.quaint.2013.03.041.

Wu, J., Huang, J., Han, X., Gao, X., He, F., Jiang, M., Jiang, Z., Primack, R.B., Shen, Z., 2004. The Three Gorges Dam: an ecological perspective. Ecol. Soc. Am., 2, 241-248.

Xiao, C., Li, P., Feng, Z., Wu, X., 2018. Spatio-temporal differences in cloud cover of Landsat-8 OLI observations across China during 2013-2016. J. Geogr. Sci., 28, 429-444. doi.org/10.1007/s11442-018-1482-0.

Yumin, T., Bingxin, B., Mohammad, M.S., 2016. Time series remote sensing based dynamic monitoring of land use and land cover change. 4th Int. Work. Earth Obs. Remote Sens. Appl. EORSA $2016 \quad$ - Proc., 202-206. doi.org/10.1109/EORSA.2016.7552797.

Zeng, Y., Schaepman, M.E., Wu, B., Clevers, J.G.P.W., Bregt, A.K., 2008. Scaling-based forest structural change detection using an inverted geometric-optical model in the Three Gorges region of China. Remote Sens. Environ., 112, 4261-4271. doi.org/10.1016/j.rse.2008.07.007.

Zhang, J., Zhengjun, L., Xiaoxia, S., 2009. Changing landscape in the Three Gorges Reservoir Area of Yangtze River from 1977 to 2005: Land use/land cover, vegetation cover changes estimated using multi-source satellite data. Int. J. Appl. Earth Obs. Geoinf., 11, 403-412. doi.org/10.1016/j.jag.2009.07.004. 